short notice ; consequently the patient may have to be transferred to a special centre. Modern techniques have altered the prognosis of pulmonary embolectomy. Both hypothermia $^{15}$ and cardio-pulmonary bypass ${ }^{16} 17$ have been utilized, and portable pump-oxygenators are now available for use at the bedside. ${ }^{18}$ Undoubtedly strenuous surgical efforts are well worth while. ${ }^{19}$ Recently K. Vossschulte and colleagues $^{20}$ have suggested that the approach to the heart by vertical division of the sternum, without the aid of either hypothermia or pump-oxygenator, is swift and permits removal of pulmonary emboli more safely than by the original method of Trendelenburg. ${ }^{3}$ They report seven completely successful cases in a series of 42 operations, but many of their failures were at a time when experience was being gained. These authors also advocate ligation of the inferior vena cava at the same operation to prevent further embolization. However, Trendelenburg's operation is still used with success. ${ }^{21}$

Lesser degrees of pulmonary embolism require a decision on whether the venous pathway to the lungs should be interrupted. Even when there is evidence of venous thrombosis in one leg the embolus may have arisen silently from the opposite one-or from the pelvis. It has been shown, however, that effective anticoagulant therapy both reduces the incidence of embolism in patients with deep-vein thrombosis and usually stops embolization when this has begun. ${ }^{22}$ Patients in Great Britain are therefore generally treated at first with anticoagulants. Nevertheless, if embolization recurs during anticoagulation therapy, ligation of a major vein would seem to be obligatory. American practice is rather more aggressive than the British in that many surgeons practise bilateral ligation of the common femoral veins ${ }^{2124}$ after extraction of any thrombus present as soon as there is any evidence of deep-vein thrombosis in the leg.

When the pelvis is suspect as a source of emboli-and this is particularly so after pelvic surgery-the vena cava should be occluded instead of the common femoral veins. This may be by simple ligation after any blood-clot lying proximally has been sucked out, ${ }^{25}$ or by plication of the vena cava, ${ }^{26}$ or the application of a Teflon clip, ${ }^{27}$ which traps clots over $2 \mathrm{~mm}$. in diameter but avoids complete obstruction to blood ascending the vessel. Continued post-operative anticoagulation and early mobilization with firm support of the leg

1 Hume, M., Arch. Surg., 1963, 87, 709.

2 Virchow, R., Gessammelte Abhandlungen zur Wissenschaftlichen Medicin. IV. Thrombose und Embolie. Frankfurt am Main. 1856.

3 Trendelenburg, F., Ann. Surg., 1908, 48, 772.

${ }^{4}$ Homans, J., New Engl. $\mathcal{F}$. Med., 1934, 211, 993.

${ }^{5}$ Cosgriff, S. W., Amer. J. Med., 1947, 3, 740.

' Uhland, H., and Goldberg, L. M., Dis. Chest, 1964, 45, 533. field, Iil. 1963 .

${ }^{8}$ Birch, C. A., Emergencies in Medical Practice. London. 1963.

- Willman, V. L., Kaiser, G. C., and Hanlon, C. R., Arch. Surg., 1965, 91, 25.

${ }_{10}$ Wagner, H. N., Sabiston, D. C., McAfee, J. G., Tow, D., and Stern, H. S., New Engl. ₹. Med., 1964, 271, 377.

11 Sabiston, D. C., and Wagner, H. N., Jnr., Ann. Surg., 1964, 160, 575.

12 Williams, J. R., and Wilcox, W. C., Amer. F. Roentgenol., 1963, 89, 333.

${ }_{12}$ Robb, G. P., and Steinberg, I., ibid., 1939, 41, 1.

${ }_{14}^{13}$ Tabb, G. P., and Steinberg, I.

14 Taylor, G. W. Unpublished.

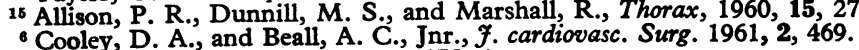

17 Sharp, E. H., Ann. Surg., 1962, 156, 1.

18 Paneth, M., Lancet, 1964, 2, 1291.

19 Cross, F. S., Jones, R. D., and Mowlem, A., Arch. Surg., 1964, 89, 159. 20 Vossschulte, K., Stiller, H., and Eisenreich, F., Surgery, 1965, 58, 317

21 Hayward, J., and Howqua, J., Lancet, 1964, 2, 771.

22 Hayward, J., and How and Jordan, S. C., ibid., 1960, 1, 1309.

${ }_{23}$ Homans, J., Amer. F. Med., 1947, 3, 345.

${ }_{24}$ Homans, J., Amer. F. Med., 19

${ }_{25}$ Linton, R. R. Unpublished. $1954,140,200$.

${ }_{26}$ Madden, J. L., Ann. Surg., 1954, 140, 200. . J. J., Kaupp, H. A., and Trippel, O. H., Arch. Surg., 1964, 88, 1016.

27 Taber, R. E., ibid., 1963, 87, 191.

${ }_{28}$ Krause, R. J., Cranley, J. J., Hallaba, M. A. S., Strasser, E. S., and Hafner, C. D., ibid., 1963, 87, 184.

so Shea, P. C., and Robertson, R. L., Surg. Gynec. Obstet., 1951, 93, 153. are essential. Although careful treatment can keep oedema of the leg to a minimum after ligation of the vena cava, ${ }^{25} 28$ the experience of some authors ${ }^{29}$ suggests that the British approach of using it only as a life-saving measure is justified.

\section{Distribution of Alcohol in the Body}

The publication of the White Paper ${ }^{1}$ on which the Government's forthcoming Road Safety Bill will be based has revived interest both in the way in which alcohol is distributed in the body and in methods of estimating concentrations of alcohol in body tissues. The paper by Professor J. P. Payne and his colleagues, which appears on page 196 of this week's issue, is therefore timely. They present the results of comprehensive studies made on both dogs and human beings of the distribution of alcohol in arterial and venous blood, in urine, and in breath. They confirm the great variability in the rate of absorption of alcohol from the stomach; in dogs the peak concentration in the blood is reached after between 45 and 120 minutes. When, however, alcohol is given directly into the duodenum, the peak concentration in the blood usually occurs within 20 minutes. These results agree with observations made in man after gastrectomy, ${ }^{2}$ in which the time relationship is similar, and patients who have had a gastrectomy should be specifically warned about the dangers of driving a car shortly after even a very small amount of alcohol.

Many of the early pharmacological measurements on the distribution of alcohol in body tissues were made by $R$. N. Harger and his team in Indianapolis. In animal experiments they showed that alcohol absorbed into the blood passed almost immediately into brain tissue. ${ }^{34}$ In contrast, equilibration was much slower between blood and muscles; venous blood from the leg contained much less alcohol than arterial blood for about the first hour ; ${ }^{35}$ ' this confirmed the findings of other workers in the U.S.A." Since, therefore, arterial blood levels would give a better index of brain alcohol concentrations and hence of cerebral function, Harger used capillary blood from a warm finger-tip as a convenient substitute for arterial blood in human subjects. For an hour after an alcoholic drink the concentration of alcohol in fingertip blood exceeded that in venous blood from the arm. ${ }^{8}$ In a subsequent study arterial blood alcohol measured in the first 30 minutes exceeded that in the finger-tip by $18 \% .^{\circ}$ In the absorptive phase, therefore, finger-tip blood alcohol was intermediate between arterial and venous levels. Alcohol measured in rebreathed air correlated best with arterial blood. ${ }^{9}$

Professor Payne and his colleagues have extended Harger's work by continuing arterial sampling for periods up to 4 hours. Their findings are substantially in agreement with those of previous workers. Thus in the early absorptive phase arterial alcohol levels rise rapidly and are distinctly higher than venous alcohol levels. After about 2 hours there is a "crossover" of arterial and venous concentrations. In the later phase, when blood alcohol concentration is slowly declining through oxidation and to a less extent excretion, alcohol returns from the tissues into the blood-stream and the venous concentration slightly exceeds the arterial. Payne and his team have presented the first convincing evidence of this phenomenon.

These observers also find a fairly good correlation between blood and urine concentrations after the peak level of urine 
alcohol has been reached. It is well known that the alcohol concentration in urine exceeds that in blood by about one third, and that urine values reflect fairly closely the venous blood values which were present about 30 minutes before the urine collection. ${ }^{1011}$ Under experimental conditions in which alcohol is taken as a single drink, and in which the time of the peak concentration in the blood is known-or can be foretold-useful deductions can be made from the analysis of a single sample of urine. But in ordinary life the subject may still be absorbing alcohol, or he may not have emptied his bladder for a long time, and in these circumstances accurate deductions of blood alcohol levels cannot be made. It is for this reason that the B.M.A.'s Alcohol and Road Accidents Committee ${ }^{12}$ recommended "that two specimens of urine should be taken, the second about 30 minutes after the first, and the results of both analyses given to the Court." This recommendation is adopted in the White Paper, ${ }^{1}$ and at a police station a suspect who objects to the taking of blood will be given the alternative of providing urine samples. The observations of Payne and his colleagues confirm the relative inaccuracy of this method of determining tissue alcohol concentration, especially if a second sample shows a higher concentration than the first. Their results emphasize how essential it is not to rely on a single urine sample.

The main point of conflict between the conclusions of Payne and his colleagues and those of other investigators concerns breath alcohol analysis. These authors conclude that " the wide variations between breath and blood analyses virtually exclude the use of breath testing for the accurate determination of blood alcohol concentration." This sweeping statement runs counter to almost all the evidence adduced by other workers, and it is necessary to look very carefully at the techniques used for analysis. The infra-red analyser which they used may be precise if all the physicochemical conditions are properly regulated, but such a method is known to be fraught with technical difficulties. It has not yet been tested by other observers, and the in vitro calibration of the instrument was apparently accurate to within only $\pm 10 \%$ when vapour in equilibrium with blood was used. It is possible that this poor correlation is due to an inherent

1 Road Safety Legislation 1965-6, Ministry of Transport, 1965, Cmnd 2859. H.M.S.O.

${ }^{2}$ Elmslie, R. G., Davis, R. A., and White, T. T., Surg. Gynec. Obstet., 1964, 119, 1256

- Harger, R. N., Hulpieu, H. R., and Lamb, E. B., f. biol. Chem., 1937, $120,689$.

- Hulpieu, H. R., and Cole, V. V., Quart. F. Stud. Alcohol, 1946, 7, 89. Harger, R. N., Hulpieu, H. R., and Cole, V. V., Fed. Proc., 1945, 4, 123. Forney, R. B., Hulpieu, H. R., and Harger, R. N., f. Pharmacol. exp.
Ther., 1950, 98, 8.

'Haggard, H. W., and Greenberg, L. A., Ibid., 1934, 52, 158.

- Harger, R. N., Forney, R. B., and Baker, R. S., Quart. f. Stud. Alcohol, 1956, 17, i.

- Harger, R. N., Alcohol and Road Traffic. Proceedings of the Third International Conference on Alcohol and Road Traffic. B.M.A., London, 1963, p. 212.

10 Drew, G. C., Colquhoun, W. P., and Long, H. A., Memor. med. Res. Coun. (Lond.), 1959, 38.

11 Hill, I. D., Brit. med.' f., 1965, 1, 383.

12 The Drinking Driver, B.M.A., London, 1965, p. 32

13 Begg, T. B., Hill, I. D., and Nickolls, L. C., Brit. med. F., 1964, 1, 9

Scroggie, J. G., Alcohol and Road Traffic. Proceedings of the Third International Conference on Alcohol and Road Traffic. B.M.A., London, 1963, p. 272.

18 Evaluating Chemical Tests for Intoxication. A Report of the Committee on Tests for Intoxication, National Safety Council, U.S.A.,

16 Wright, B. M., Brit. med. 7., 1965, 2, 1430.

17 Burger, E., Zibl. Verkehrs-Med. Mr. $1959,1430$.

1. Monnier, D., Chron. int. Pol., 1961, No. 49.

10 Lins, G., and Randonat, H. W., Disch. Z. ges. gerichtl. Med., 1962, 52, 242 .

20 Dubowski, K. M., Alcohol and Road Traffic. Proceedings of the Third International Conference on Alcohol and Road Traffic. B.M.A., London, 1963, p. 203.

21 Grosskopf, K., Ibid., p. 281. lack of reliability in the new method of breath analysis. This could have been checked if the authors had compared their results with those given by a well-established instrument such as the Breathalyzer or Kitagawa-Wright apparatus. On theoretical grounds breath is to be preferred to venous blood for analysis, since it is in equilibrium with arterial blood. It is true that the Breathalyzer, for example, tends to underestimate the blood alcohol level, but the underestimate is not gross. ${ }^{13} 14$ In one well-designed study, ${ }^{13}$ in which observations were confined to the post-absorptive phase, when breath and venous blood values should correspond, the correlation between these values was in fact impressively close, and the results of breath analysis were notably consistent. Other workers in this country ${ }^{1016}$ have also found a good correlation between blood and breath alcohol levels. Moreover, in the U.S.A. the view of the National Safety Council, ${ }^{15}$ which is generally accepted, is that: "Tests made on instruments for breath analysis if conducted in the manner prescribed by the authors of the respective methods will give comparable and reliable results for estimating the concentration of alcohol in the blood."

Payne and his colleagues describe one other finding which is at variance with those of other workers, and which has some practical importance. In two instances they found unexpectedly high alcohol levels in the breath 40 and 45 minutes after a drink had been taken. It is well recognized that a "mouth-alcohol" effect may persist for some time after drinking, but none of the numerous investigators who have reported their results has found this to be longer than 20 minutes. ${ }^{13}$ 17-21 $^{1}$ Difficulties can arise with breath testing apparatus if tests are made too early, or if the subject vomits, regurgitates, or belches. These possibilities must be taken into account in any screening test. In general, however, as Payne and his colleagues point out, the tendency of breath tests to underestimate blood alcohol is advantageous to the suspect, and is a point in their favour when they are used as an aid to law enforcement.

\section{Medical Microbiology as a Career}

In his recent Foundation Lecture to the College of Pathologists, published at page 189 of the B.M.F. this week, Dr. J. W. Howie, Director of the Public Health Laboratory Service, poses four questions, all concerned with the training, status, and functions of those doing diagnostic bacteriology. The lecture begins with the interesting statement, which will be news to many people, that " in most parts of the world," other than Britain, "progressively fewer young doctors are making careers for themselves in medical microbiology." In some countries, including the United States, much of this work has for long been done by science graduates.

A general falling off in recruitment from the ranks of medicine in other countries than ours could have important consequences if we accept the lecturer's own answer to his first question. This is simply whether a training in medicine and general pathology is necessary to the proper practice of medical bacteriology. Dr. Howie supports an affirmative answer with several telling anecdotes illustrating the value to the bacteriologist of a clinical training. Perhaps one example he gives is rather extreme-namely, of a bacteriologist who was the first person connected with a patient to recognize rather obvious signs of appendicitis-but other 